\title{
Epithelial and endothelial mesenchymal transition and their role in diabetic kidney disease
}

\author{
Farahnaz Dadras $^{1}$, Vida Sheikh ${ }^{2}$, Farhad Khoshjou ${ }^{2 *}$ \\ ${ }^{1}$ Department of Internal Medicine, Section of Nephrology, Iran University of Medical Sciences, Tehran, Iran \\ ${ }^{2}$ Clinical Research Development unit of Shahid Beheshti Hospital, Hamadan University of Medical Sciences, Hamadan, Iran
}

\begin{tabular}{l} 
A R T I C L E I N F O \\
\hline Article Type: \\
Mini-Review \\
\hline Article History: \\
Received: 3 July 2017 \\
Accepted: 10 September 2017 \\
Published online: 4 December 2017 \\
Keywords: \\
Endothelial mesenchymal \\
transition, Diabetic nephropathy, \\
TGF $\beta /$ Smad, Integrin /ILK, Wnt/ $\beta$ - \\
catenin, Diabetic kidney disease, \\
Endothelial mesenchymal transition
\end{tabular}

\begin{abstract}
A B S T R A C T
Diabetic nephropathy (DN) is the main cause of end-stage renal disease. On the other hand, there are a couple of evidences, including human studies, which prove the role of epithelial mesenchymal transition (EMT) in pathophysiology of DN. EMT is characterized by loss of epithelial proteins and gain of mesenchymal markers. EMT is induced via three main conduit; TGF $\beta / S m a d$, integrin /ILK as well as Wnt/ $\beta$-catenin pathways. Besides, numerous studies illustrated how drugs and agents can modify this phenomenon. On the other hand, endothelial mesenchymal transition (EndoMT) has a well-known role in pathophysiology of diabetic nephropathy which has been studied in animal and human. Here, several drugs and modifiers which have been studied to ffigure out if they can amend nature of EMT or EndoMT are reported briefly.
\end{abstract}

Implication for health policy/practice/research/medical education:

Diabetes and its complications including diabetic nephropathy are spreading worldwide. On the other hand, pathophysiology of diabetic kidney disease and its modifiers have been studied broadly. This mini-review presents a couple of them, allocated to EMT and Endomt, briefly and to the point.

Please cite this paper as: Dadras F, Sheikh V, Khoshjou F. Epithelial and endothelial mesenchymal transition and their role in diabetic kidney disease. J Renal Inj Prev. 2018;7(1):1-6. DOI: 10.15171/jrip.2018.01.

\section{Introduction}

Diabetic kidney disease (DKD) is a major complication of diabetes and is the single largest cause of endstage kidney failure (1). During the clinically silent stage, structural lesions include glomerular basement membrane thickening build up and extreme deposition of extracellular matrix (ECM) in the glomerulus and interstitial area. It, finally, leads to glomerulosclerosis and tubulointerstitial fibrosis as well $(2,3)$. Pathophysiology of diabetic nephropathy (DN) has intensively been studied. Two of them i.e. epithelial-mesenchymal transition (EMT) and endothelial-mesenchymal transition (EndoMT) are discussed here. Furthermore, a couple of drugs and agents which modify these phenomena are listed.

\section{Materials and Methods}

For this mini-review, we used a variety of sources including PubMed, Embase, Scopus and directory of open access journals (DOAJ). The search was performed by using combinations of the following keywords and or their equivalents; epithelial mesenchymal transition, diabetic nephropathy, TGF $\beta /$ Smad, integrin /ILK, Wnt/ $\beta$-catenin, diabetic kidney disease and endothelial mesenchymal transition. Manuscripts published in English as full-text articles and or as abstracts were included in the study.

\section{Epithelial-mesenchymal transition}

Epithelial cells are connected exteriorly to basement membrane and interiorly cover the lumen of tubules. 
Sideways, they interrelate with adjacent epithelial cells (4). Epithelial-mesenchymal transition (EMT) comprises loss of intercellular connections, their detachment from a basement membrane, loss of epithelial phenotype markers and attain mesenchymal markers and cell progression (5). The transition is characterized by loss of epithelial proteins such as cytokeratin, and E-cadherin and take mesenchymal markers including $\alpha$-smooth muscle actin (a-SMA) and vimentin (6). However, the possession of EMT markers in vivo, is often variable, perhaps reflecting limited EMT (also termed pre-EMT) (7).

EMT might be an adaptive reaction of epithelial cells to an aggressive milieu. The chemokine slope made about tubular sections draw inflammatory cells to the tubulointerstitial space. They, in turn, generate matrix metalloproteinases (MMPs) and pro-fibrotic cytokines, accordingly (8).

MMPs, especially MMP-2 and MMP-9, secreted by macrophages and up-regulated by TGF- $\beta 1$ in kidney tubular epithelial cells, have been shown to be pro-fibrotic by induction of tubular cells EMT (9).

MMP-9 decays normal basement membrane collagen and postpones degradation and endorses gathering of extracellular matrix (10). There is disordered ratio of MMP-9 and tissue inhibitor of metalloproteinase in EMT (11), including the EMT which takes place in DKD (12). Glomerular podocytes and endothelial cells also experience transition after damage. Phenotypic modification of podocytes leads to proteinuria and glomerulosclerosis (13). EMT is induced via three main conduits, three main converging signaling pathways, which they are TGF $\beta /$ Smad, integrin/ILK, and Wnt/ $\beta$-catenin pathways (Figure 1).

\section{TGF $\beta$ signaling}

Tian et al explained that the cytoskeleton of proximal tubular epithelial cells undertakes notable restructuring in reaction to TGF- $\beta$ (14). They lose their cobblestone morphology and become spindle shaped.

This is accompanied by downregulation of expression of E-cadherin, a key constituent of adherents junctions, de

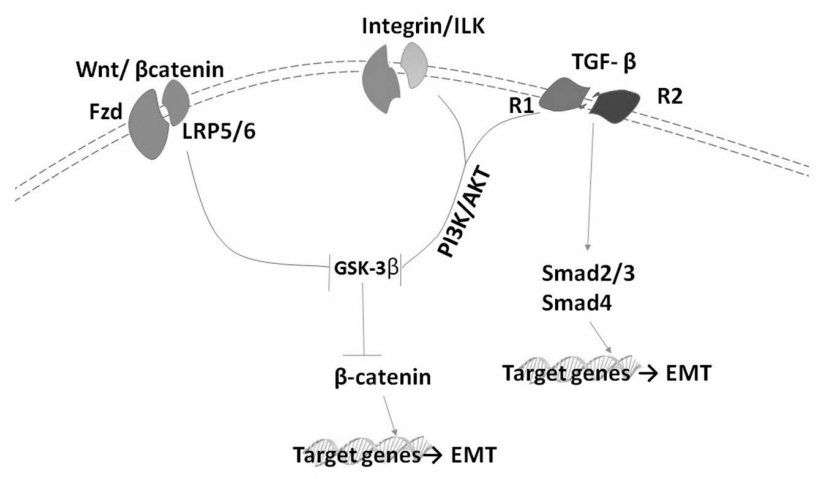

Figure 1. Three main signaling pathways which lead to expression of EMT genes novo expression of $\alpha$-SMA and reformation of the actin microfibrillar which is characteristic of myofibroblasts. Smad proteins principally mediate the signals of TGF- $\beta$. Non-Smad pathways of TGF- $\beta$ signaling complicated in EMT comprise RhoA, p38 mitogen-activated protein kinase (MAPK), and phosphatidyl-3-kinase(PI3K)/AKT. Rho kinase, on the other hand, can be motivated by sphingosine-1-phosphate (S1P) through its receptor, S1P2. Thus, S1P-S1P2 signaling takes part in EMT through Rho kinase activation in renal tubules (15).

\section{Integrin/ILK signaling}

Integrin linked kinase (ILK) obtains its biologic actions by two major characteristics; as a protein kinase and as a scaffolding protein (16). As a protein kinase, the catalytic activity of ILK renders it to directly phosphorylate a number of downstream kinases including GSK-3- $\beta$ causes stabilization of $\beta$-catenin (17). This sequentially organizes the presentation of a cluster of genes that are fundamental for the EMT phenomenon.

\section{Wnt/ $\beta$ catenin signaling}

In the lead of fastening to their receptors, Wnt proteins provoke a successive signaling, involving GSK-3- $\beta$. It, in turn, consequences in $\beta$-catenin escaping from ubiquitinmediated degradation. As a result $\beta$-catenin accumulates in the cytoplasm and translocates into the nuclei, where it stimulates the transcription of Wnt target genes (18).

\section{Endothelial mesenchymal transition (EndoMT)}

For the first time, Karasek suggested that endothelial cells (EC) are a source of myofibroblasts in fibrotic diseases (19). During EndoMT, endothelial cells (EC) lose their molecular markers such as VE-cadherin, detach from endothelial layer and begin the expression of mesenchymal cell products (e.g. a-SMA) (20).

\section{Molecular mechanisms of EndoMT}

TGF- $\beta$-binding activates Smad-dependent and Smadindependent signaling. Consequently, inception of NOX4 emergence results in Snail1 provocation of EndoMT. Endothelin-1 wields strong collaboration with TGF- $\beta$ effects on EndoMT, as well. Snail1 levels are modulated by GSK3-mediated phosphorylation.

Caveolins, on the other hand, are a family of essential membrane proteins that are involved in receptorindependent endocytosis. Caveolin-1 is most prominently expressed in endothelial, fibrous, and adipose tissue (21). It causes TGF- $\beta$ receptors internalization and successive deprivation (22) (Figure 2).

Evidence of EMT in diabetic nephropathy Stimulation of the Wnt/ $\beta$-catenin signaling pathway has been verified to play a role in the pathogenesis and progression of $\mathrm{DN}$, and multiple cells are considered to be involved in this process, including mesangial cells, 


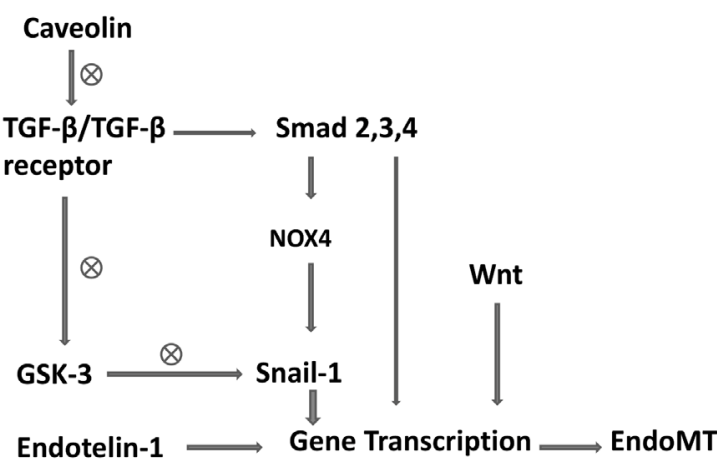

Figure 2. Molecular factors which induce EndoMT.

endothelial cells, podocytes and tubular cells (23). Zhou et al showed that levels of $\beta$-catenin and WNT proteins are upregulated in the kidney tissues of diabetic animal models. Furthermore, activated WNT signaling in cultured human renal proximal tubular epithelial cells and proteinuria induced by hyperglycemic milieu, could be ameliorated by using the antibody (24).

\section{MicroRNAs}

Micro (mi)RNAs are small noncoding endogenous RNA strands that regulate gene expression. For instance expression of miRNA192 downregulated by TGF $\beta$ correlates with fibrosis in human DN (25). On the other hand, expression of miRNA377 was upregulated in murine models of $\mathrm{DN}$, which led to amplified fibronectin production (26).

\section{Other mediators}

Dai et al showed that high-glucose induces EMT and connective tissue growth factor (CTGF) overexpression in podocytes which can be attenuated by anti-CTGF antibody (27). On the other hand, cytochrome P450 (CYP) epoxygenases metabolize arachidonic acid into epoxyeicosatrienoic acids (EETs). TGF- $\beta$ linhibition induced by CYP2J2 expression distinguishes key function of this axis in pathophysiology DN (28).

Furthermore, high glucose-induced phenotypic transition in podocytes is provoked by PTEN/PI3K/Akt pathway (29). High-mobility group AT-hook 2 (HMGA2) plays an important role in EMT during DKD, as well (30).

\section{Role of EndoMT in diabetic kidney disease}

Endothelial dysfunction has been postulated to take part in the pathogenesis of DN. Both afferent and efferent arterioles and glomerular endothelial cells (GEnC) all are damaged (31). Zeisberg et al presented the first evidence of possible EndoMT in diabetic kidney fibrosis (32). They showed that roughly half of fibroblasts expressed both endothelial marker and markers of fibroblasts and myofibroblasts simultaneously.

Advanced oxidation protein products (AOPP) are uremic toxins formed during oxidative stress through the reaction of plasma proteins with chlorinated oxidants such as hypochlorous acid or chloramines. A study by Liang et al showed; AOPP treatment drops expression of vascular endothelial CD31 and cadherin and induces overexpression of $\alpha$-smooth muscle actin and vimentin, additionally. They conclusively showed that AOPPs prompts EndoMT (33).

Rho-associated kinase 1 (ROCK1) is a protein serine/ threonine kinase. It controls the actomyosin cytoskeleton and contributes to processes such as cell motility and EMT (34). Peng et al displayed that ROCK1 is induced by high glucose and it consequently stimulates EndoMT and causing amplified endothelial permeability. Therefore inhibition of ROCK1 might be a therapeutic approach for avoiding glomerular endothelial dysfunction in emerging DN (35).

Inhibitors of dipeptidyl peptidase 4 or gliptins are a category of oral hypoglycemic agents which can be used to treat diabetes mellitus type 2. The DPP-4 inhibitor linagliptin, as

Shi et al showed, amends endothelial levels of integrin $\beta 1$. Furthermore, knock downing of DPP-4 results in the suppression of TGF- $\beta$ receptor heterodimer formation, and EndoMT, as well (36).

Acetyl-seryl-aspartyl-lysyl-proline (AcSDKP) is a substrate of angiotensin-converting enzyme (ACE) and an endogenous anti-fibrotic molecule that has the potential of inhibition of the EndoMT through the restoration of FGF receptor (37).

Serum response factor is a member of transcription factors. This protein regulates the activity of many genes and takes part in cell differentiation. Increased serum response factor (SRF) activity provokes both EMT in podocytes (38) and EndoMT of GEnCs in DKD. Targeting SRF by small molecule inhibitors (e.g. CCG-1423) is suggested as an attractive therapeutic approach for DKD (39).

SMADs are transducer proteins that transmit extracellular signals from TGF- $\beta$ ligands to the nucleus where they stimulate downstream gene transcription.

Obstruction of EndoMT by Smad3 inhibitor offers a new approach to delay the advancement of diabetic complications including DKD (40).

Human studies

EMT has also been recognized in biopsies of patients with DN (41) and also vimentin immunoreactivity was severely illustrated in atrophic diabetic tubules (42).

$\mathrm{Li}$ et al showed that ZO-1 and nephrin disappear in the glomeruli of human diabetic kidneys. On the other hand, FspI, is induced in glomerular podocytes (43).

Peng et al demonstrated that EndoMT occurs in the glomerular endothelium of patients with $\mathrm{DKD}$, showing by a decrease in CD31 but an increase in a-SMA expression (35).

Protein $\mathrm{C}$ is an anticoagulant serine protease activated 
by the blood coagulation pathway (44). Endothelial protein $\mathrm{C}$ receptor (EPCR) is a receptor for protein $\mathrm{C}$ that enhances its activation. EPCR delays DN progress. On the other hand, EPCR shedding through metalloproteinase ADAM17 contributes to the worsening of DKD (45).

\section{Modifiers and drugs}

A couple of agents and drugs have been studied to show their impact on EMT induced by hyperglycemia (Table 1).

\section{Conclusion}

Numerous studies, including experimental animal models and tissues from patients, undoubtedly, make obvious that EMT and EndoMT cooperate a significant role in the pathogenesis of DKD. Several studies evidently point out the explanation of molecular mechanisms implicated in EMT and EndoMT, making novel molecular targets and therapeutic approaches, available to DKD.

\section{Authors' contribution}

FD designed the study. VS collected the data. FK was the study supervisor, contributed to all aspect of the study and provided the final manuscript. All authors read and approved the paper.

\section{Conflicts of interest}

The authors declare no conflict of interest.

Ethical considerations

Ethical issues (including plagiarism, data fabrication,

Table 1. List of some drugs or modifiers of EMT

\begin{tabular}{lc}
\hline Modifier name & Subject \\
\hline Mycophenolate mofetil \pm benazepril (46) & Rat \\
Chrysin (47) & RPTEC \& mice \\
Zn (48) & NRK-52E cells \\
B-Casomorphin-7 (49) & NRK-52E cells \\
Curcumin (50) & NRK-52E cells \\
Resveratrol (51) & HK-2 cells \\
Benidipine (52) & Rat \\
Losartan + paricalcitol (53) & Mice \\
Tempol (54) & Rat \\
Troglitazone (55) & Primary renal proximal \\
Oxymatrine (56) & cell \\
NSC697923 (inhibitor of UBE2N-Ueva1A & NRK52E \\
complex) (57) & HK2 cells \\
miR-26a and miR-30c (58) & NRK52E \\
Mesenchymal stem cell (59) & Mice \\
Roscovitine (60) & NRK52E \\
Fucoidan (61) & Rat \\
eEOC \& BMP5 (62) & C57/B16N mice \\
\hline
\end{tabular}

Abbreviations: RPTEC, human renal proximal tubular epithelial cell; NRK-52E cells, normal rat kidney tubular epithelial cell line; HK-2 cells, human tubular epithelial cells; eEOC, early endothelial outgrowth cells; BMP: bone morphogenetic protein. double publication) have been completely observed by the authors.

\section{Funding/Support}

None.

\section{References}

1. Foley RN, Collins AJ. End-stage renal disease in the United States: an update from the United States Renal Data System. J Am Soc Nephrol. 2007;18:2644-8. doi: 10.1681/ asn.2007020220.

2. Marshall CB. Rethinking glomerular basement membrane thickening in diabetic nephropathy: adaptive or pathogenic? Am J Physiol Renal Physiol. 2016;311:F831-f43. doi: 10.1152/ajprenal.00313.2016.

3. Loeffler I, Wolf G. Epithelial-to-Mesenchymal Transition in Diabetic Nephropathy: Fact or Fiction? Cells. 2015;4:63152. doi: $10.3390 /$ cells 4040631 .

4. Thiery JP, Acloque H, Huang RYJ, Nieto MA. EpithelialMesenchymal Transitions in Development and Disease. Cell. 2009;139:871-90. doi: 10.1016/j.cell.2009.11.007.

5. Kalluri R, Weinberg RA. The basics of epithelialmesenchymal transition. J Clin Invest. 2009;119:1420-8. doi: $\quad 10.1172 /$ jci39104.

6. Liu Y. Epithelial to mesenchymal transition in renal fibrogenesis: pathologic significance, molecular mechanism, and therapeutic intervention. J Am Soc Nephrol. 2004;15:112. doi: 10.1097/01.ASN.0000106015.29070.E7.

7. Hertig A, Anglicheau D, Verine J, Pallet N, Touzot M, Ancel PY, et al. Early epithelial phenotypic changes predict graft fibrosis. J Am Soc Nephrol. 2008;19:1584-91. doi: 10.1681/ asn.2007101160.

8. Strutz F, Neilson EG. New insights into mechanisms of fibrosis in immune renal injury. Springer Semin Immunopathol. 2003;24:459-76. doi: 10.1007/s00281-0030123-5.

9. Zhao H, Dong Y, Tian X, Tan TK, Liu Z, Zhao Y, et al. Matrix metalloproteinases contribute to kidney fibrosis in chronic kidney diseases. World J Nephrol. 2013;2:84-9. doi: 10.5527/wjn.v2.i3.84.

10. Bai Y, Wang L, Li Y, Liu S, Li J, Wang H, et al. High ambient glucose levels modulates the production of MMP-9 and alpha5(IV) collagen by cultured podocytes. Cell Physiol Biochem. 2006;17:57-68. doi: 10.1159/000091464.

11. Wang XY, Wang Y, Liu HC. Tamoxifen lowers the MMP-9/TIMP-1 ratio and inhibits the invasion capacity of ER-positive non-small cell lung cancer cells. Biomed Pharmacother. 2011;65:525-8. doi: 10.1016/j. biopha.2011.06.002.

12. Rysz J, Banach M, Stolarek RA, Pasnik J, Cialkowska-Rysz A, Koktysz R, et al. Serum matrix metalloproteinases MMP2 and MMP-9 and metalloproteinase tissue inhibitors TIMP-1 and TIMP-2 in diabetic nephropathy. J Nephrol. 2007;20:444-52.

13. Liu Y. New insights into epithelial-mesenchymal transition in kidney fibrosis. J Am Soc Nephrol. 2010;21:212-22. doi: 10.1681/asn.2008121226.

14. Tian YC, Fraser D, Attisano L, Phillips AO. TGF-beta1mediated alterations of renal proximal tubular epithelial 
cell phenotype. Am J Physiol Renal Physiol. 2003;285:F13042. doi: 10.1152/ajprenal.00408.2002.

15. Ishizawa S, Takahashi-Fujigasaki J, Kanazawa Y, Matoba K, Kawanami D, Yokota T, et al. Sphingosine-1-phosphate induces differentiation of cultured renal tubular epithelial cells under Rho kinase activation via the S1P2 receptor. Clin Exp Nephrol. 2014;18:844-52. doi: 10.1007/s10157014-0933-x.

16. Legate KR, Montanez E, Kudlacek O, Fassler R. ILK, PINCH and parvin: the tIPP of integrin signalling. Nat Rev Mol Cell Biol. 2006; 7:20-31. doi: 10.1038/nrm1789.

17. Hannigan G, Troussard AA, Dedhar S. Integrin-linked kinase: a cancer therapeutic target unique among its ILK. Nat Rev Cancer. 2005;5:51-63. doi: 10.1038/nrc1524.

18. Moon RT, Kohn AD, De Ferrari GV, Kaykas A. WNT and beta-catenin signalling: diseases and therapies. Nat Rev Genet. 2004;5:691-701. doi: 10.1038/nrg1427.

19. Karasek MA. Does transformation of microvascular endothelial cells into myofibroblasts play a key role in the etiology and pathology of fibrotic disease? Med Hypotheses. 2007;68:650-5. doi: 10.1016/j.mehy.2006.07.053.

20. $\mathrm{Hu}$ B, Phan SH. Myofibroblasts. Curr Opin Rheumatol. 2013;25:71-7. doi: 10.1097/BOR.0b013e32835b1352.

21. Williams TM, Lisanti MP. The caveolin proteins. Genome Biol. 2004;5:214. doi: 10.1186/gb-2004-5-3-214.

22. Piera-Velazquez S, Mendoza FA, Jimenez SA. Endothelial to Mesenchymal Transition (EndoMT) in the Pathogenesis of Human Fibrotic Diseases. J Clin Med. 2016;5:45. doi: $10.3390 / \mathrm{jcm} 5040045$.

23. Lin CL, Wang JY, Huang YT, Kuo YH, Surendran K, Wang FS. Wnt/beta-catenin signaling modulates survival of high glucose-stressed mesangial cells. J Am Soc Nephrol. 2006;17:2812-20. doi: 10.1681/asn.2005121355.

24. Zhou T, He X, Cheng R, Zhang B, Zhang RR, Chen Y, et al. Implication of dysregulation of the canonical winglesstype MMTV integration site (WNT) pathway in diabetic nephropathy. Diabetologia. 2012;55:255-66. doi: 10.1007/ s00125-011-2314-2.

25. Krupa A, Jenkins R, Luo DD, Lewis A, Phillips A, Fraser D. Loss of MicroRNA-192 promotes fibrogenesis in diabetic nephropathy. J Am Soc Nephrol. 2010;21:438-47. doi: 10.1681/asn.2009050530.

26. Wang Q, Wang Y, Minto AW, Wang J, Shi Q, Li X, et al. MicroRNA-377 is up-regulated and can lead to increased fibronectin production in diabetic nephropathy. Faseb j. 2008;22:4126-35. doi: 10.1096/fj.08-112326.

27. Dai H, Zhang Y, Yuan L, Wu J, Ma L, Shi H. CTGF mediates high-glucose induced epithelial-mesenchymal transition through activation of beta-catenin in podocytes. Ren Fail. 2016;38:1711-6. doi: 10.3109/0886022x.2016.1158069.

28. Chen G, Wang P, Zhao G, Xu G, Gruzdev A, Zeldin DC, et al. Cytochrome P450 epoxygenase CYP2J2 attenuates nephropathy in streptozotocin-induced diabetic mice. Prostaglandins Other Lipid Mediat. 2011;96:63-71. doi: 10.1016/j.prostaglandins.2011.06.009.

29. Xing L, Liu Q, Fu S, Li S, Yang L, Liu S, et al. PTEN Inhibits High Glucose-Induced Phenotypic Transition in Podocytes. J Cell Biochem. 2015;116:1776-84. doi: 10.1002/jcb.25136.

30. Bai YH, Wang JP, Yang M, Zeng Y, Jiang HY. SiRNA-HMGA2 weakened AGEs-induced epithelial-to-mesenchymal transition in tubular epithelial cells. Biochem Biophys Res Commun. 2015;457:730-5. doi: 10.1016/j.bbrc.2015.01.063.

31. Cheng H, Harris RC. Renal endothelial dysfunction in diabetic nephropathy. Cardiovasc Hematol Disord Drug Targets. 2014;14:22-33. doi: 10.2174/1871529X146661404 01110841.

32. Zeisberg EM, Potenta SE, Sugimoto H, Zeisberg M, Kalluri R. Fibroblasts in kidney fibrosis emerge via endothelial-tomesenchymal transition. J Am Soc Nephrol. 2008;19:22827. doi: 10.1681/asn.2008050513.

33. Liang X, Duan N, Wang Y, Shu S, Xiang X, Guo T, et al. Advanced oxidation protein products induce endothelialto-mesenchymal transition in human renal glomerular endothelial cells through induction of endoplasmic reticulum stress. J Diabetes Complications. 2016;30:573-9. doi: $\quad$ 10.1016/j.jdiacomp.2016.01.009.

34. Riento K, Ridley AJ. Rocks: multifunctional kinases in cell behaviour. Nat Rev Mol Cell Biol. 2003;4:446-56. doi: 10.1038/nrm1128.

35. Peng H, Li Y, Wang C, Zhang J, Chen Y, Chen W, et al. ROCK1 Induces Endothelial-to-Mesenchymal Transition in Glomeruli to Aggravate Albuminuria in Diabetic Nephropathy. Sci Rep. 2016;6:20304. doi: 10.1038/ srep20304.

36. Shi S, Srivastava SP, Kanasaki M, He J, Kitada M, Nagai T, et al. Interactions of DPP-4 and integrin betal influences endothelial-to-mesenchymal transition. Kidney Int. 2015;88:479-89. doi: 10.1038/ki.2015.103.

37. Nagai $T$, Kanasaki M, Srivastava SP, Nakamura Y, Ishigaki Y, Kitada M, et al. N-acetyl-seryl-aspartyl-lysylproline inhibits diabetes-associated kidney fibrosis and endothelial-mesenchymal transition. Biomed Res Int. 2014;2014:696475. doi: 10.1155/2014/696475.

38. Zhao L, Wang X, Sun L, Nie H, Liu X, Chen Z, et al. Critical role of serum response factor in podocyte epithelialmesenchymal transition of diabetic nephropathy. Diab Vasc Dis Res. 2016;13:81-92. doi: 10.1177/1479164115588545.

39. Zhao L, Zhao J, Wang X, Chen Z, Peng K, Lu X, et al. Serum response factor induces endothelial-mesenchymal transition in glomerular endothelial cells to aggravate proteinuria in diabetic nephropathy. Physiol Genomics. 2016;48:711-8. doi: 10.1152/physiolgenomics.00082.2016.

40. Li J, Qu X, Yao J, Caruana G, Ricardo SD, Yamamoto Y, et al. Blockade of endothelial-mesenchymal transition by a Smad3 inhibitor delays the early development of streptozotocin-induced diabetic nephropathy. Diabetes. 2010;59:2612-24. doi: 10.2337/db09-1631.

41. Rastaldi MP, Ferrario F, Giardino L, Dell'Antonio G, Grillo C, Grillo P, et al. Epithelial-mesenchymal transition of tubular epithelial cells in human renal biopsies. Kidney Int. 2002;62(1):137-46. doi: 10.1046/j.1523-1755.2002.00430.x.

42. Essawy M, Soylemezoglu O, Muchaneta-Kubara EC, Shortland J, Brown CB, el Nahas AM. Myofibroblasts and the progression of diabetic nephropathy. Nephrol Dial Transplant. 1997;12:43-50.

43. Li Y, Kang YS, Dai C, Kiss LP, Wen X, Liu Y. Epithelialto-mesenchymal transition is a potential pathway leading to podocyte dysfunction and proteinuria. Am J Pathol. 2008;172:299-308. doi: 10.2353/ajpath.2008.070057.

44. Palta S, Saroa R, Palta A. Overview of the coagulation system. 
Indian J Anaesth. 2014;58:515-23. doi: 10.4103/00195049.144643.

45. Lattenist L, Ochodnicky P, Ahdi M, Claessen N, Leemans JC, Satchell SC, et al. Renal endothelial protein C receptor expression and shedding during diabetic nephropathy. J Thromb Haemost. 2016;14:1171-82. doi: 10.1111/jth.13315.

46. Xiao X, Wang J, Chang X, Zhen J, Zhou G, Hu Z. Mycophenolate mofetil ameliorates diabetic nephropathy through epithelial mesenchymal transition in rats. Mol Med Rep. 2015;12:4043-50. doi: 10.3892/mmr.2015.3934.

47. Kang MK, Park SH, Choi YJ, Shin D, Kang YH. Chrysin inhibits diabetic renal tubulointerstitial fibrosis through blocking epithelial to mesenchymal transition. J Mol Med (Berl). 2015;93:759-72. doi: 10.1007/s00109-015-1301-3.

48. Zhang X, Liang D, Chi ZH, Chu Q, Zhao C, Ma RZ, et al. Effect of zinc on high glucose-induced epithelial-tomesenchymal transition in renal tubular epithelial cells. Int J Mol Med. 2015;35:1747-54. doi: 10.3892/ijmm.2015.2170.

49. Zhang W, Song S, Liu F, Liu Y, Zhang Y. Beta-casomorphin-7 prevents epithelial-mesenchymal transdifferentiation of NRK-52E cells at high glucose level: Involvement of AngII-TGF-beta1 pathway. Peptides. 2015;70:37-44. doi: 10.1016/j.peptides.2015.04.002.

50. Zhang X, Liang D, Guo L, Liang W, Jiang Y, Li H, et al. Curcumin protects renal tubular epithelial cells from high glucose-induced epithelial-to-mesenchymal transition through Nrf2-mediated upregulation of heme oxygenase-1. Mol Med Rep. 2015;12:1347-55. doi: 10.3892/ mmr.2015.3556.

51. He T, Guan X, Wang S, Xiao T, Yang K, Xu X, et al. Resveratrol prevents high glucose-induced epithelial-mesenchymal transition in renal tubular epithelial cells by inhibiting NADPH oxidase/ROS/ERK pathway. Mol Cell Endocrinol. 2015;402:13-20. doi: 10.1016/j.mce.2014.12.010.

52. Wu G, Xu M, Xu K, Hu Y. Benidipine protects kidney through inhibiting ROCK1 activity and reducing the epithelium-mesenchymal transdifferentiation in type 1 diabetic rats. J Diabetes Res. 2013;2013:174526. doi: $10.1155 / 2013 / 174526$.

53. Zhang Z, Zhang Y, Ning G, Deb DK, Kong J, Li YC. Combination therapy with AT1 blocker and vitamin $\mathrm{D}$ analog markedly ameliorates diabetic nephropathy: blockade of compensatory renin increase. Proc Natl Acad Sci U S A. 2008;105:15896-901. doi: 10.1073/pnas.0803751105.
54. Jafari M, Dadras F, Ghadimipour HR, Seif Rabiei MA, Khoshjou F. Tempol effect on epithelial-mesenchymal transition induced by hyperglycemia. J Nephropathol. 2017;6:1-4. doi: 10.15171/jnp.2017.01.

55. Lee YJ, Han HJ. Troglitazone ameliorates high glucoseinduced EMT and dysfunction of SGLTs through PI3K/ Akt, GSK-3beta, Snaill, and beta-catenin in renal proximal tubule cells. Am J Physiol Renal Physiol. 2010;298:F126375. doi: 10.1152/ajprenal.00475.2009.

56. Liu L, Wang Y, Yan R, Li S, Shi M, Xiao Y, et al. Oxymatrine Inhibits Renal Tubular EMT Induced by High Glucose via Upregulation of SnoN and Inhibition of TGF-beta1/Smad Signaling Pathway. PLoS One. 2016;11:e0151986. doi: 10.1371/journal.pone.0151986.

57. Pontrelli P, Conserva F, Papale M, Oranger A, Barozzino M, Vocino G, Rocchetti MT, et al. Lysine 63 ubiquitination is involved in the progression of tubular damage in diabetic nephropathy. FASEB J. 2017;31:308-319. doi: 10.1096/ fj.201600382RR.

58. Zheng Z, Guan M, Jia Y, Wang D, Pang R, Lv F, et al. The coordinated roles of miR-26a and miR-30c in regulating TGFbeta1-induced epithelial-to-mesenchymal transition in diabetic nephropathy. Sci Rep. 2016;6:37492. doi: 10.1038/srep37492.

59. Nagaishi K, Mizue Y, Chikenji T, Otani M, Nakano M, Konari N, et al. Mesenchymal stem cell therapy ameliorates diabetic nephropathy via the paracrine effect of renal trophic factors including exosomes. Sci Rep. 2016;6:34842. doi: $10.1038 /$ srep34842.

60. Bai X, Hou X, Tian J, Geng J, Li X. CDK5 promotes renal tubulointerstitial fibrosis in diabetic nephropathy via ERK1/2/PPARgamma pathway. Oncotarget. 2016;7:3651028. doi: 10.18632/oncotarget.9058.

61. Chen J, Cui W, Zhang Q, Jia Y, Sun Y, Weng L, et al. Low molecular weight fucoidan ameliorates diabetic nephropathy via inhibiting epithelial-mesenchymal transition and fibrotic processes. Am J Transl Res. 2015;7:1553-63.

62. Patschan D, Schwarze K, Henze E, Becker JU, Patschan S, Muller GA. eEOC-mediated modulation of endothelial autophagy, senescence, and EnMT in murine diabetic nephropathy. Am J Physiol Renal Physiol. 2014;307:F68694. doi: 10.1152/ajprenal.00650.2013.

Copyright (C) 2018 The Author(s); Published by Nickan Research Institute. This is an open-access article distributed under the terms of the Creative Commons Attribution License (http://creativecommons.org/licenses/by/4.0), which permits unrestricted use, distribution, and reproduction in any medium, provided the original work is properly cited. 